\title{
PERANCANGAN WIRLESS STARTER KENDARAAN BERMOTOR MEMANFAATKAN BLUETOOTH BERBASIS ARDUINO
}

\author{
${ }^{1}$ Ending Susanti, ${ }^{2}$ Nelvan Candra \\ Program Studi Teknik Elektro,Universitas Riau Kepulauan Batam \\ lendang_unrika@yahoo.co.id
}

\begin{abstract}
Abstrak
Sepeda motor merupakan salah satu alat transportasi yang banyak digunakaan pada saat ini dimana penggunaan sepeda motor dinilai lebih efien dalam segi waktu dan tenaga akan tetapi karena kesibukan pengguna cendrung melupakan perawatan sederhana pada sepeda motor yaitu memanaskan nya terlebih dahulu sebelum pagi hari sepeda motor digunakan. Pada penelitian ini dirancang sebuah alat yang dapat mempermudah setiap pengguna sepeda motor memanaskan sepeda motor dengan starter otomatis melalui aplikasi bluetooth. Dengan dirancangnya alat ini diharapkan dapat mempermudah pengguna dalam perawatan sepeda motor. Bluetooth merupakan sebuah teknologi komunikasi nirkabel (tanpa kabel) yang beroperasi pada frekuensi $2.5 \mathrm{Ghz}$. Pada perancangan ini dibuat suatu alat yang dipasang pada sepeda motor dengan menggunakan kontrol arduino yang dapat menyalakan mesin dan mematikan kembali yang dapat diakses melalui smartphone dengan memanfaatkan bluetooth. Arduino sendiri merupakan pengendali mikro single board yang bersifat open source, diturunkan dari wiring platform, dirancang untuk memudahkan penggunan elektronik dalam berbagai bidang.
\end{abstract}

Kata kunci : Bluetooth, Smartphone, Arduino

\section{PENDAHULUAN}

Perkembangan teknologi sekarang ini pada bidang telekomunikasi sangat memberikan dampak yang sangat besar dalam kehidupan sehari-hari. Hal tersebut dibuktikan dengan semakin bertambahnya penemuanpenemuan yang canggih dan modern, yang sangat membantu manusia dalam beraktivitas dan terlebih-lebih dalam hal peralatan elektronik.

Alat komunikasi Smartphone berbasis android salah satu alat komunikasi yang berkembang saat ini, karena alat komunikasi ini dapat digunakan untuk berkomunikasi dan juga dapat dimanfaatkan sebagai kontrol peralatan elektronik. Aplikasi handphone ini dapat digunakan sebagai sistem pengendali jarak jauh seperti pengendalian pada starter mesin sepeda motor.[1]

Sepeda motor juga merupakan sebuah alat transportasi yang sangat membantu dalam setiap perjalanan sehari-hari, yang lebih efisien waktu dan juga tenaga. Hal yang terpenting juga adalah tidak melupakan perawatan motor agar tidak cepat mengalami kerusakan pada mesin. 
Dalam hal ini perawatan tidak hanya pada saat membawanya ke bengkel tetapi juga dengan rutin memanaskannya terlebih dahulu sebelum mengendarainya. Namun hal ini juga sering diabaikan oleh setiap pengendara karna berbagai kesibukan ataupun karna malas. Oleh karena itu, pada penelitian ini dirancang sebuah alat yang dapat mempermudah setiap pengguna sepeda motor dengan starter otomatis melalui aplikasi bluetooth. Prinsip kerjanya sendiri adalah ketika alat ini dipasang pada sepeda motor dengan menggunakan arduino maka program akan memberi perintah untuk menyalakan mesin dan mematikan kembali yang dapat diakses melalui handphone.

Adapun rancangan dan pembuatan alat ini menggunakan mikrokontroler ATMega 328, yang difungsikan sebagai pegendali atau kontroler yang memberikan perintah pada relay agar aktif (ON) dengan kondisi logika "high or low". Komponen lain yang juga digunakan yaitu bluetooth HC5 yang berfungsi sebagai penghubung antara handphone dengan sepeda motor.

\section{LANDASAN TEORI}

\subsection{Bluetooth}

\section{A. Pengertian Bluetooth}

Bluetooth adalah sebuah nama produk industri komunikasi yang diperuntukkan bagi Personal Area Network (PAN). Nama bluetooth diambil dari nama seorang raja, Harald Bluetooth pada abad ke-X. Teknologi bluetooth dapat menghubungkan berbagai macam perangkat komunikasi untuk dapat melakukan pertukaran informasi misalnya Smartphone, komputer, notebook, dan lain-lain. Gelombang radio yang digunakan adalah short range radio frequency tanpa lisensi. Artinya untuk menggunakan teknologi bluetooth tidak dibutuhkan lisensi khusus untuk pemanfaatan jalur frekuensi. Jarak jangkau dari gelombang radio hanya mencapai 1 meter sampai 100 meter karena itu disebut dengan short-range. Standar dari bluetooth dibuat oleh Bluetooth Special Interest Group. [3]

Bluetooth merupakan sebuah teknologi komunikasi nirkabel (tanpa kabel) yang beroperasi pada frekuensi 2.5 Ghz. Komunikasi pada bluetooth sangat erat kaitannya dengan jaringan piconet. Sebuah piconet paling sederhana terdiri dari dua buah 
peralatan bluetooth dimana yang satu menginisialisasi koneksi sebagai master (pengirim), sedangkan perangkat lain yang menerima dinamakan sebagai slave. Untuk bisa bertukar data melalui bluetooth, maka kedua perangkat yang akan dihubungkan harus melakukan pairing terlebih dulu. Pairing adalah proses pencarian perangkat oleh discover (pencari) pada discoverable (yang dicari), serta melakukan autentikasi (kemampuan suatu perangkat dalam mengenali perangkat lain ketika saling berkomunikasi).[3]

\section{B. Cara Kerja Bluetooth}

Pada Gambar 1. menunjukkan bagaimana Bluetooth device melakukan koneksi ke dalam piconet. Piconet terdiri dari sebuah master device dan active slave devices, dimana jumlah maksimum active slaves adalah 7. Kumpulan dari beberapa piconet yang saling berhubungan disebut dengan scatternets [3].

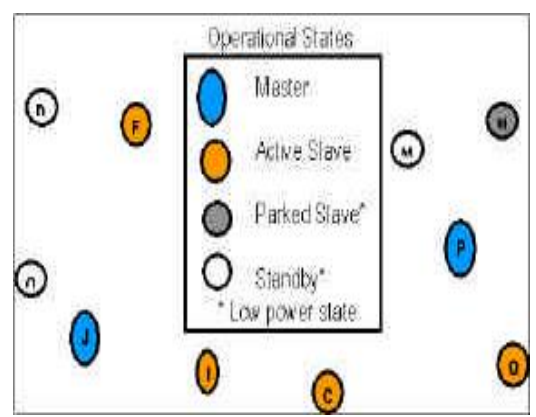

Gambar 2.1Operational State of Bluetooth[3]

Bluetooth devices mempunyai 4 basicstates. Antaralain adalah master (yangmengontrol sebuah piconet), active slave(terhubung dan secara aktif memonitorPiconet), parked slave (secara logik masihbagian dari piconet tetapi low power,),dan standby (tidak terhubung denganpiconet).

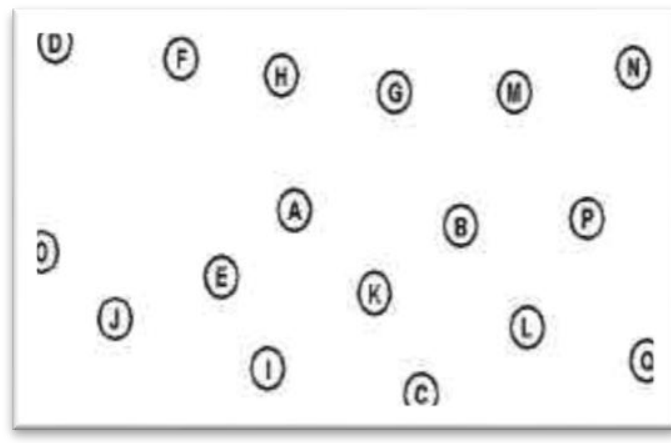

Gambar 2.2 Bluetooth pada Awalnya [3] 


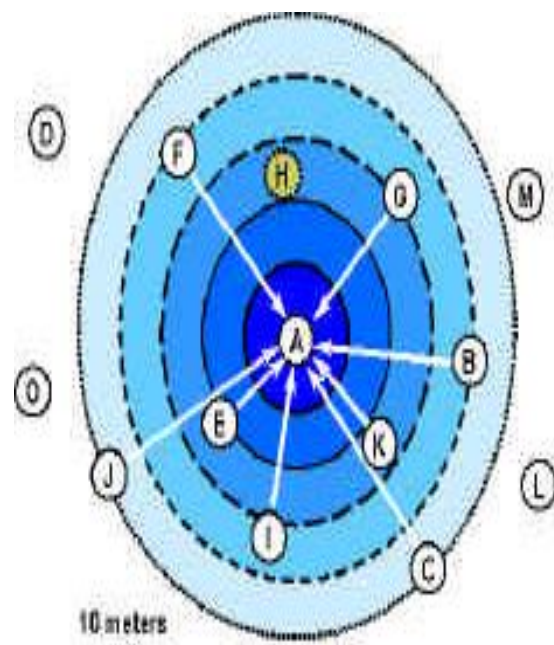

(1)

(D)

Gambar 2.3 Proses Inquiry Bluetooth [3]

Inquiry adalah suatu proses bagaimanaBluetooth device belajar tentangbluetooth devices lain yang ada di dalamjangkauannya. Pada Gambar 3, node Amengeluarkan fungsi page pada BTInquiry ID dan menerima balasan daridevices $\mathrm{B}, \mathrm{C}$, E, F, G, I, J, and K. Daribalasan ini, A mengetahui identitas daridevices lain (contohnya, Bluetooth deviceID mereka yang unik).

Node $\mathrm{H}$ pada Gambar 2.3 menunjukkanbagaimana sebuah Bluetooth device dapatdiprogram sebagai anonymous (Undiscoverable).

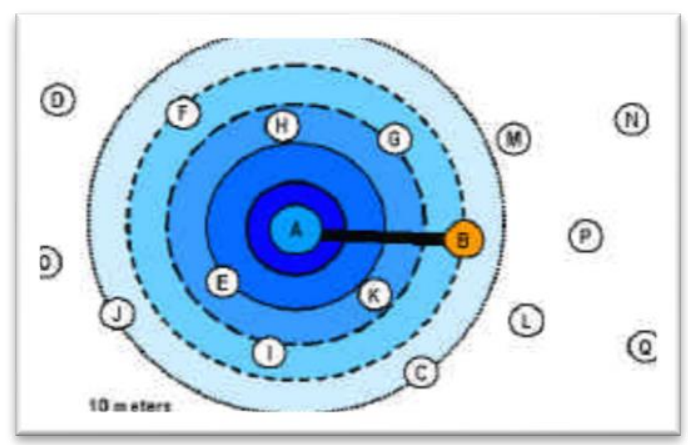

Gambar 2.4 Proses Paging Bluetooth [3]

Setelah proses inquiry, akan dilakukanproses paging, dimana pada prosesini akan dibangun hubungan antar device(antar master sebagai pemuladengansebuah slave. Hubungan master/slavepada bluetooth dikenal dengan sebutanpiconet.

Untuk menciptakan piconet, device Amelakukan broadcasts Page commanddengan explicit device ID dari slave target(pada gambar di atas adalah B) yangtelah siap. Semua bluetooth deviceskecuali $\mathrm{B}$ akan mengabaikan perintah inikarena tidak ditujukan pada mereka.

Ketika device $\mathrm{B}$ membalas, device Aakan mengirim sebuah FHS packetkembali dan menetapkannya sebagaiActive Member Address pada Piconet.Sebagai active slave, device $\mathrm{B}$ mulaimemonitor secara terus-menerus perintahdari selanjutnya dari device A. 
Sebuah bluetooth master dapatmelakukan proses paging ini denganmaksimum 7 active slaves. 7 merupakanbatas atas karena hanya disediakan 3 bitspada Bluetooth untuk Active MemberAddress (AMA) dengan 000 disediakanuntuk master dan sisanya untuk slaves.Sekali lagi, semua active slaves ke A akanmemonitor secara terus-menerus untukperintah yang ditujukan kepada merekadalam sinkronisasi dengan device A'shopping pattern.

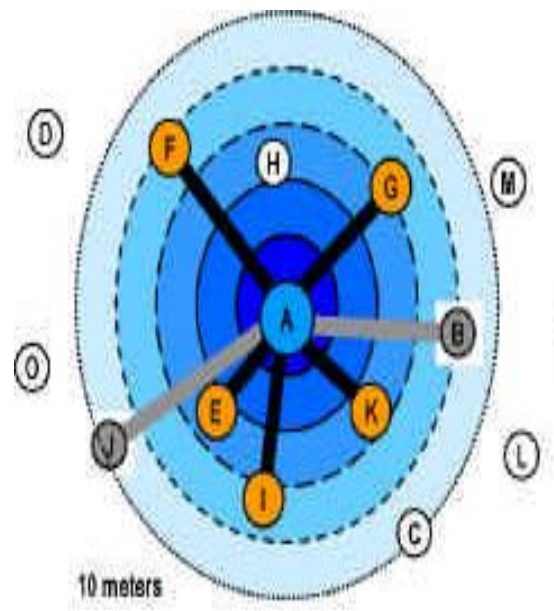

Gambar 2.5 Proses Parking [3]

Parking merupakan mekanisme yangmengijinkan Bluetooth Master untukberhubungan dengan 256 devices tambahan.256 adalah batas atas karenadisediakan 8 bits pada Bluetooth untukParked Member Address (PMA).
Untuk memarkirkan sebuah device,Bluetooth

Master mengeluarkan

Parkcommand terhadap sebuah active slavedan menetapkannya sebagai PMA. Slaveini kemudian memasuki mode parked danmenyerahkan AMA-nya. Sebagai sebuahparked slave, device akan berubah kedalam mode passive dan hanya memonitorperintahperintah pada occasionalbasis.

(D)

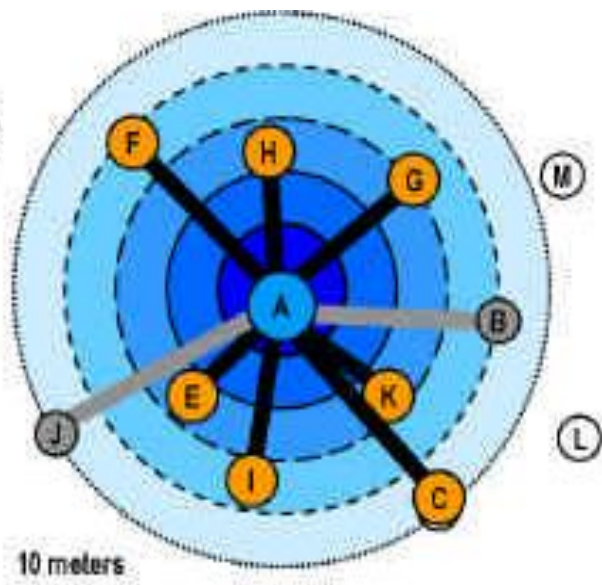

Gambar

2.6.

Proses

MengembangkanPiconet [3]

Dengan adanya

Active

MemberAddresses yang dilepaskan oleh sebuahactive slaves, Bluetooth Master dapatmelakukan proses paging dengan devicelain untuk menjadi Active Slaves. PadaGambar 6, device A menambahkan $\mathrm{H}$ dan C ke dalam piconet-nya dengan AMAsyang dilepaskan oleh parking nodes $\mathrm{B}$ dan $\mathrm{J}$. 


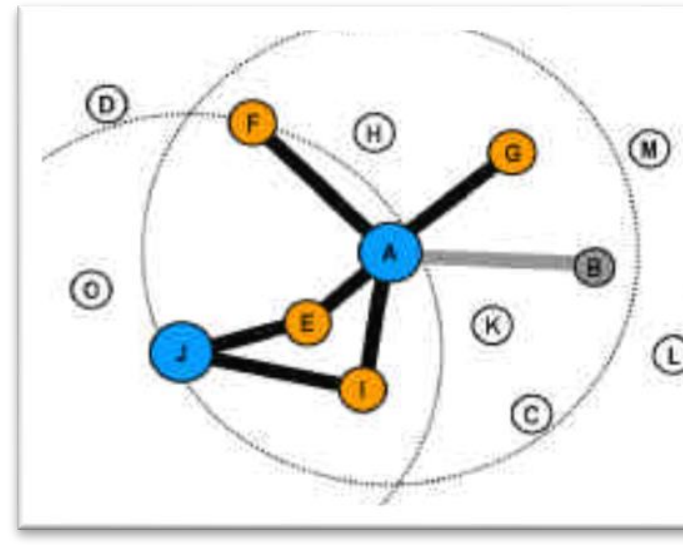

Gambar 2.7. Scatternet

Tiap bluetooth node dapat menjadibagian dari beberapa piconets sekaligusdalam satu waktu. Hal ini membuat beberapa piconets dapat bergabungmembentuk sebuah struktur yang disebutscatternet. Pada Gambar 7, dua piconetsbergabung menjadi sebuah scatternetmelalui slaves E dan I.

\section{Bluetooth HC-05}

Salah satu hasil contoh modul Bluetooth yang paling banyak digunakan adalah tipe HC-05. modul Bluetooth HC-05 merupakan salah satu modul Bluetooth yang dapat ditemukan dipasaran dengan harga yang relatif murah. Modul Bluetooth HC-05 terdiri dari 6 pin konektor, yang setiap pin konektor memiliki fungsi yang berbeda - beda. Untuk gambar module bluetooth dapat dilihat pada gambar 2.1 dibawah ini:

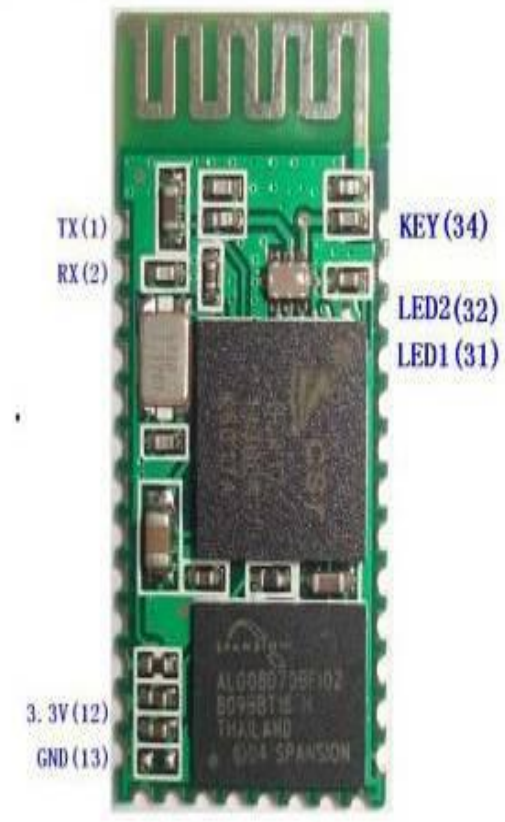

Gambar 2.8Modul Bluetooth HC-05

Modul Bluetooth HC-05 dengan supply tegangan sebesar 3,3 V ke pin 12 modul Bluetooth sebagai VCC. Pin 1 pada modul Bluetooth sebagai transmitter. kemudian pin 2 pada Bluetooth sebagai receiver.

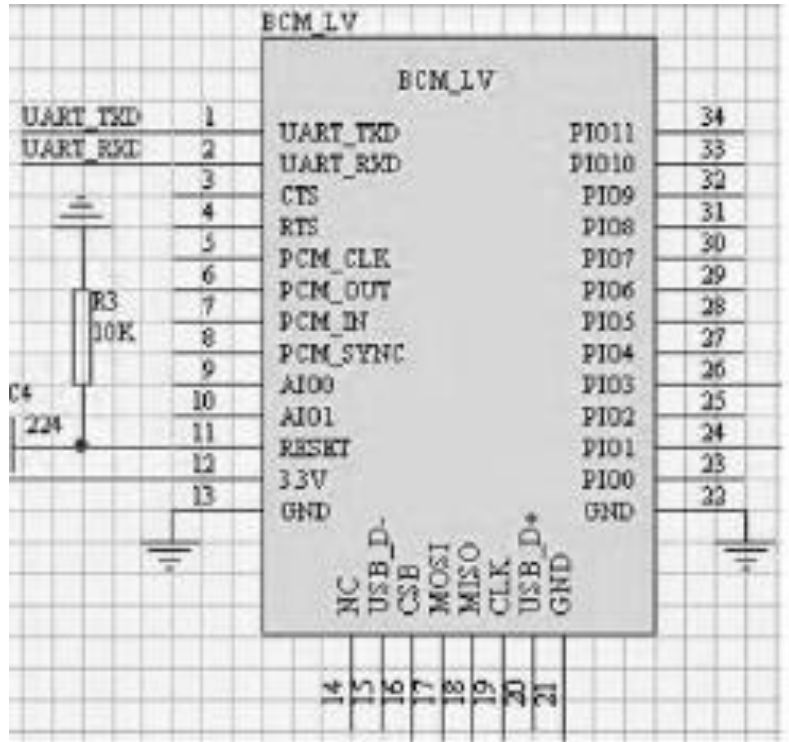

Gambar 2.9 Konfigurasi Pin Modul Bluetooth HC-05 [6]

2.2 Arduino UNO 
Arduino sendiri merupakan pengendali mikro single board yang bersifat open source, diturunkan dari wiring platform, dirancang untuk memudahkan penggunan elektronik dalam berbagai bidang. Hardwarenya memiliki prosesor Atmel AVR dan softwarenya memiliki bahasa pemrograman sendiri.Bahasa yang digunakan dalam pemrograman arduino bukanlah bahasa assembler yang relatif sulit tetapi bahasa $\mathrm{C}$ yang disederhanakan dengan bantuan pustaka (library) pada Arduino UNO berbeda dari semua board mikrokontroller yang belum menggunakan chip khusus driver FTDI USB to serial. Sebagai penggantinya penerapan USB to serial adalah ATMega16U2 versi R2, $U N O$ dilengkapi resistor ke 8U2 ke garis ground yang lebih mudah diberikan ke mode DFU.

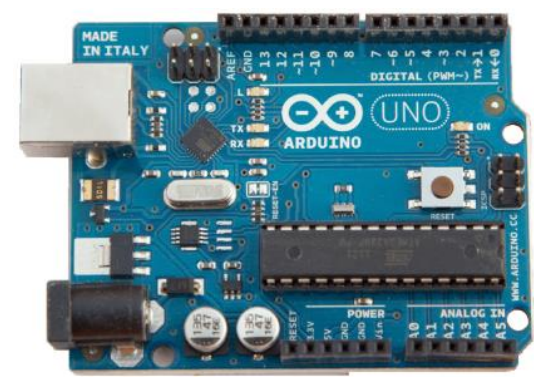

Gambar 2.10 Arduino UNO

Tabel 1 Spesifikasi Arduino

\begin{tabular}{|l|l|l|}
\hline NO. & Nama & Spesifikasi \\
\hline
\end{tabular}

\begin{tabular}{|c|c|c|}
\hline 1. & $\begin{array}{l}\text { Microcontrol } \\
\text { ler }\end{array}$ & $\begin{array}{l}\text { ATMega3 } \\
28 p\end{array}$ \\
\hline 2. & $\begin{array}{l}\text { Operating } \\
\text { Voltage }\end{array}$ & $5 \mathrm{~V}$ \\
\hline 3. & $\begin{array}{l}\text { Input } \\
\text { Voltage } \\
\text { (recommand } \\
\text { ed) }\end{array}$ & $7-12 \mathrm{~V}$ \\
\hline 4. & $\begin{array}{l}\text { Input } \\
\text { Voltage } \\
\text { (limit) }\end{array}$ & $6-20 \mathrm{~V}$ \\
\hline 5. & $\begin{array}{l}\text { Digital I/O } \\
\text { Pin }\end{array}$ & $\begin{array}{l}14 \text { (of } \\
\text { which } 6 \\
\text { provide } \\
\text { PWM } \\
\text { output) }\end{array}$ \\
\hline 6. & $\begin{array}{l}\text { PWM } \\
\text { Digital I/O } \\
\text { Pin }\end{array}$ & 6 \\
\hline 7. & $\begin{array}{l}\text { Analog Input } \\
\text { Pin }\end{array}$ & 6 \\
\hline 8. & $\begin{array}{l}\text { DC Current } \\
\text { per I/O Pin }\end{array}$ & $20 \mathrm{~mA}$ \\
\hline 9. & $\begin{array}{l}\mathrm{DC} \text { Current } \\
\text { for } 3.3 \mathrm{~V} \text { Pin }\end{array}$ & $50 \mathrm{~mA}$ \\
\hline 10. & $\begin{array}{l}\text { Flash } \\
\text { Memory }\end{array}$ & $\begin{array}{l}\text { 32KB } \\
\text { (ATMega } \\
328 \mathrm{P} \text { ) } \\
\text { of which } \\
0.5 \mathrm{~KB} \\
\text { used by } \\
\text { bootloader }\end{array}$ \\
\hline 11. & SRAM & $\begin{array}{l}\text { 2KB } \\
\text { (ATMega } \\
328 \mathrm{P})\end{array}$ \\
\hline 12. & EEPROM & $\begin{array}{l}1 \mathrm{~KB} \\
(\mathrm{ATMega} \\
328 \mathrm{P})\end{array}$ \\
\hline $\mathrm{NO}$ & Nama & Spesifikasi \\
\hline 13. & Clock Speed & $16 \mathrm{MHz}$ \\
\hline 14. & Length & $68.6 \mathrm{~mm}$ \\
\hline
\end{tabular}




\subsection{Relay}

Relay adalah sebuah saklar yang dikendalikan oleh arus. Relay memiliki sebuah inti. Terdapat sebuah artmatur besi yang akan tertarikmenuju inti apabila arus yang mengalirmelewati kumparan. Artmatur ini terpasang pada sebuah tuas pegas. Ketika artmatur tertarikmenuju inti, kotak jalur yang bersamaan akan berubah posisinya dari kontak normal tertutup kekontak normal terbuka [9].

Konstruksi dalam suatu relay terdiri dari lilitan kawat (coil) yang dililitkan pada intibesi lunak. Jika lilitan kawat mendapatkan aliran arus, inti besi lunak kontak menghasilkanmedan magnet dan menarik switch kontak. Dan pemakaian jenis relay tergantung pada kadaanyang diinginkan dalam suatu rangkaian.Menurut kerjanya relay dapat dibedakan menjadi :

a. Normaly Open $(O N)$, saklar akan terbuka bila dialiri arus

b. Normaly Close (OFF), saklar akan tertutup bila dialiri arus

c. Change Over (CO), relay ini mempunyai saklar tunggal yang normalnyatertutup yang lama, bila kumparan 1 dialiri arus maka saklar akan terhubungke terminal A, sebaliknya bila kumparan 2 dialiri arus maka saklar akan terhubung ke terminal B.

Modul relay 4 channel dilengkapi dengan optocoupler isolation yang berfungsi untuk melindungi perangkat dari arus berlebih. Berikut adalah spesifikasinya:

1. Input relay $5 \mathrm{~V}$ DC

2. Maksimum load 250VAC/10A 30VDC/10A

3. Dilengkapi dengan optocoupler isolation untuk melindungi board microcontroller dari tegangan $\mathrm{AC}$

4. Memiliki LED indikator

5. Menggunakan terminal block sehingga pemasangan kabel menjadi mudah

6. Output keluaran 4 channel maksimal 10A 
Sigma Teknika, Vol.1, No.2 : 207-225

November 2018

E-ISSN 2599-0616

P ISSN 2614-5979

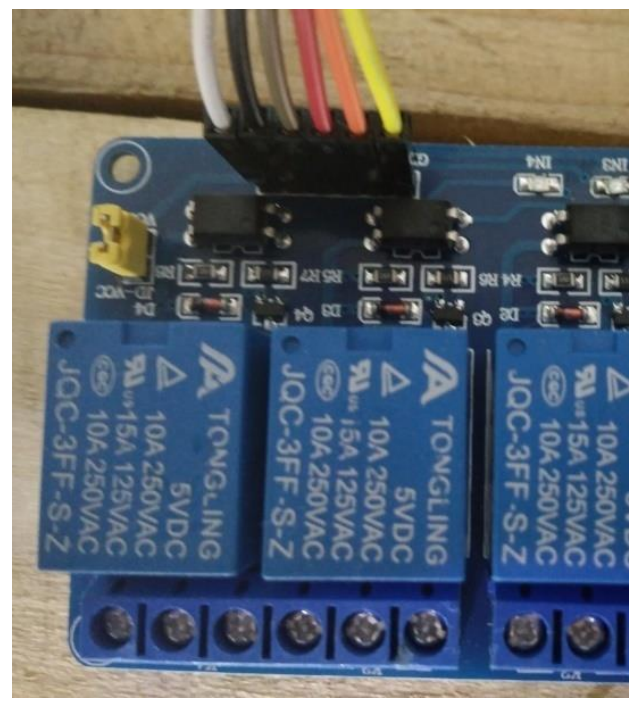

Gambar 2.12 Relay 4 Channel

\subsection{Catudaya}

Catu Daya adalah suatu alat listrik yang dapat menyediakan energi listrik untuk perangkat listrik ataupun elektronika lainnya. Pada dasarnya Power Supply atau Catu daya ini memerlukan sumber energi listrik yang kemudian mengubahnya menjadi energi listrik yang dibutuhkan oleh perangkat elektronika lainnya. Oleh karena itu, Power Supply kadang-kadang disebut juga dengan istilah Electric Power Converter. [10]

Pada perancangan ini akan dibuat sebuah rangkaian yang akan digunakan untuk menurunkan tegangan pada sumber kelistrikan pada kendaraan (Accu) dari 12 VDC menjadi 9 VDC yang digunakan sebagaisumber tegangan pada Mikrokontroler.

IC 7809 merupakan jenis IC regulator tegangan yang bisa bekerja tanpa adanya komponen tambahan. Seri 7809 berarti tegangan yang akan keluarnya adalah dari tegangan 12 VDC bisa diturunkan menjadi 9 VDC.

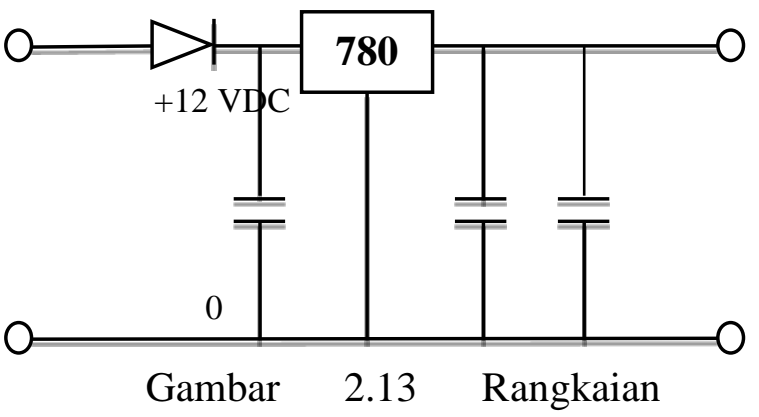

Regulator 9V

\section{Perancangan Sistem}

Perancangan dilakukan dengan menerapkan hasil desain yang telah dibuat kedalam bahasa pemgrograman (Coding), sehingga prosedur-prosedur yang telah dibuat dapat dimengerti oleh mesin mikrokontroler sehingga dapat menghasilkan output seperti yang kita harapkan.

\subsection{Blok Diagram}

Berikut ini adalah blok diagram pada perancangan alat Wireless Starter Kendaraan Bermotor 
menggunakan Bluetooth berbasis

Arduino.

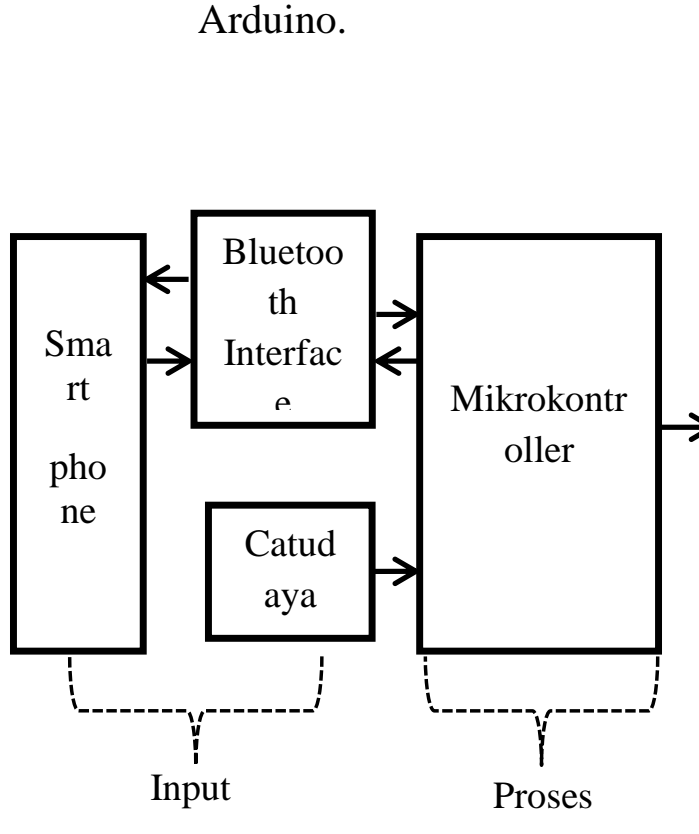

Gambar 3.3Blok Diagram Alat

Berikut adalah keterangan di

diagram

1. Input

a. Bluetooth HC-05 berfungi untuk melakukan pairing ke perangkat

Smartphone,dengan

ini

smarphone dapat melakukan

perintah yang diteruskan ke

mikrokontroler .

b. Catudaya sebagai sumber teganganpada komponen,

mengubah tegangan yang besar menjadi kecil sesuai dengan kebutuhan tegangan pada rangkaian.

2. Proses
Proses pada perancangan ini dilakukan oleh Arduino Uno sebagai pusat control dari semua rangkaian sistem yang telah diprogram dan memiliki beberapa tegangan input.

Output

Output pada perancangan ini adalah Relay sebagai saklar otomatis yang di kontrol oleh mikrokontroler sesuai dengan perintah dari user.

Desain perangkat ini menggunakan smartphone sebagai kendali jarak jauh sepeda motor dengan menggunakan bluetooth sebagai jalur akses. Apabila kontak on maka tombol start mesin dapat berfungsi. Pada saat membuka aplikasi dan menghubungkan dengan bluetooth yang terpasang pada perangkat lalu diteruskan ke mikrokontroler. Setelah terhubung user dapat menekan tombol 1 untuk menghidupkan/mematikan sistem kelistrikkan mesin, kemudian menekan tombol 2 untuk menyalakan mesin dan tombol 3 untuk alarm/klakson. Untuk menyalakan mesin user terlebih dahulu melakukan 1 (kontak ON) setelah menekan 
tonbol 1, lalu menekan tombol 2 (Start). Apabila kontak dalam keadaan OFF maka starter tidak akan menyala.

\subsection{Wiring Sistem}

Berikut adalah skema wiring pada rangkaian

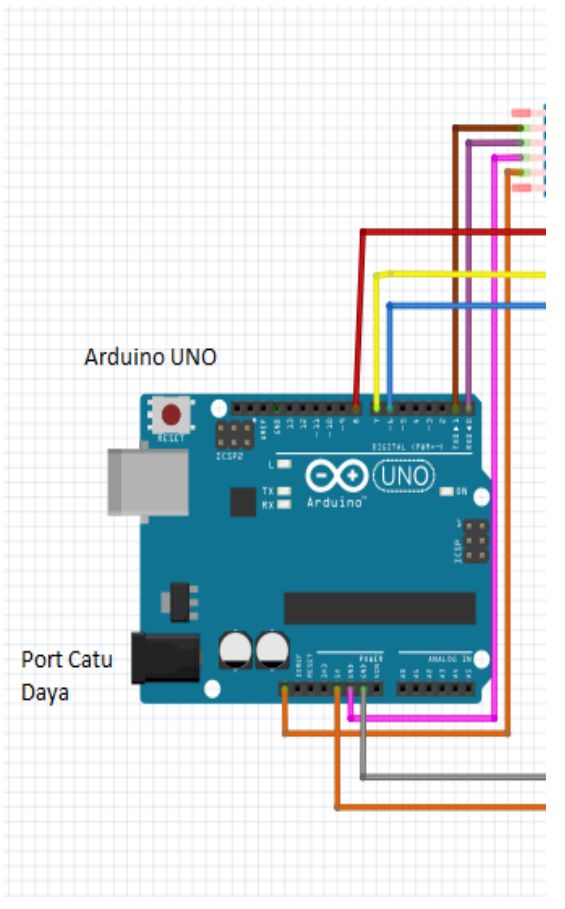

Gambar 3.4 Skema Wiring

Berikut adalah koneksi setiap

Pin Arduino keseluruh rangkaian yang dapat dilihat pada tabel 3.3.

Tabel 3.3 Koneksi Pin Arduino

\begin{tabular}{|l|l|l|}
\hline No & Kode Pin & Terhubung ke \\
\hline 1 & Pin0 (RX) & Pin TXD HC-05 \\
\hline 2 & Pin1 (TX) & Pin RXD HC-05 \\
\hline 3 & Pin 6 & Pin In-1 Relay \\
\hline 4 & Pin 7 & Pin In-2 Relay \\
\hline
\end{tabular}

\begin{tabular}{|l|l|l|}
\hline 5 & Pin 8 & Pin In-3 Relay \\
\hline 6 & Pin 3.3V & Pin VCC HC-05 \\
\hline 7 & Pin 5V & Pin VCC Relay \\
\hline 8 & GND & Pin GND Relay \\
\hline 9 & GND & Pin GND HC-05 \\
\hline
\end{tabular}

\subsection{Flow Chart Sistem}

Berikut ini adalah flowchart perancangan sistem berbasis arduino

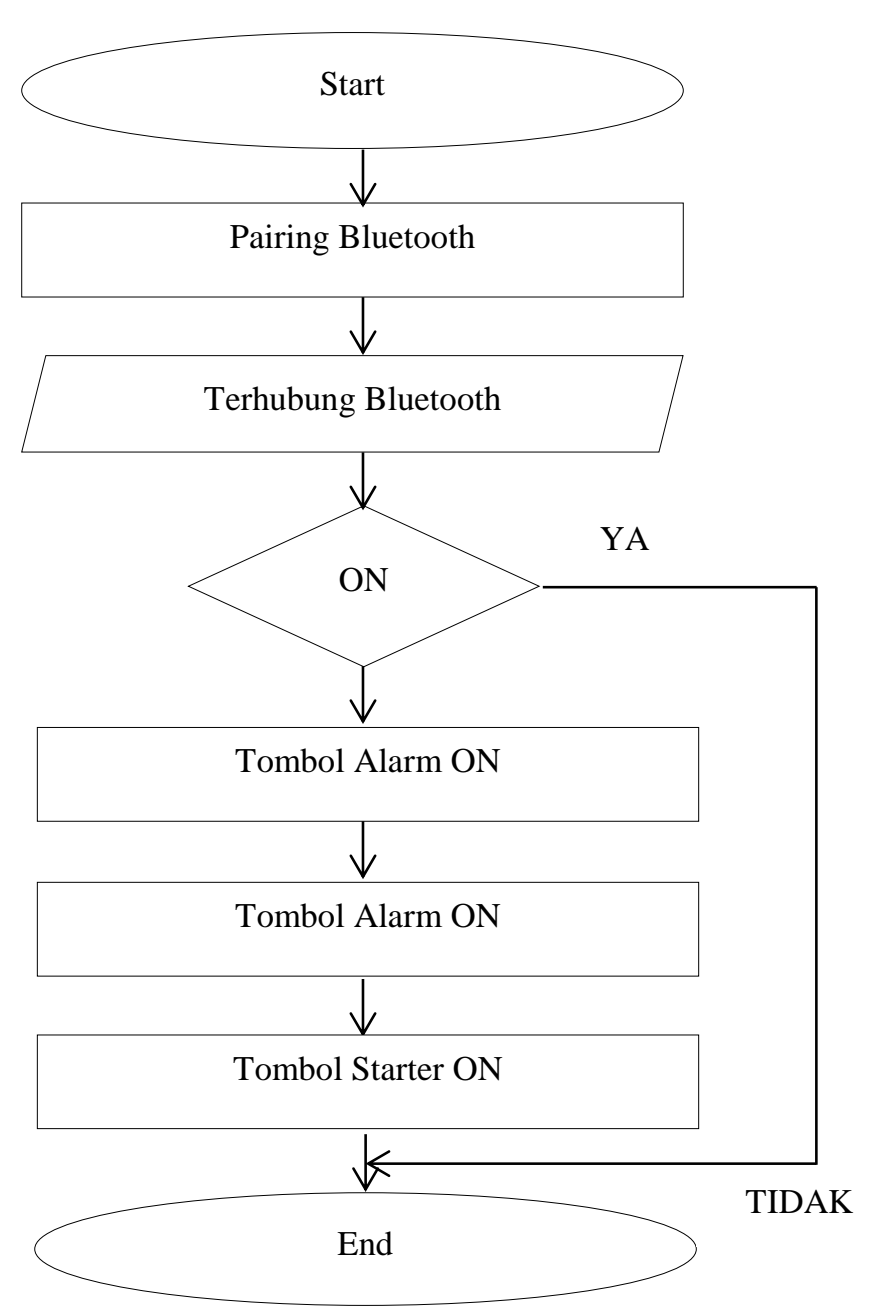

Gambar 3.5 Flow Chart Sistem

Smartphone android akan menyambungkan dengan Bluetooth 
Module HC-05 pada Arduino, Bluetooth module akan menerima autentikasi dari android. Dengan ini, android dapat melakukan perintah Kontak ON, Starter ON dan Klakson ON.

Sistem ini diimplementasikan pada sepeda motor Supra X 125D dan smartphone android yang digunakan adalah MI Redmi 4A. Aplikasi ini dapat bekerja di android versi Jelly Bean, Lollipop, Marshmallow dengan aplikasi Bluetooth. Penggunaan sistem ini dapat membantu user dalam menyalakan mesin sepeda motor dari jarak tertentu.

\subsection{Pengujian dan Pengambilan Data}

Setelah sistem selesai dibuat, maka perlu dilakukan pengujian terhadap sistem tersebut. Berikut adalah skenario yang akan diuji pada rangkaian Wireless Strater Kendaraan Bermotor dengan Memanfaatkan Bluetooth berbasis Arduino.

1. Menguji seberapa jauh jarak responBluetooth dari smartphone keModul Bluetooth HC-05

2. Pengujian dilakukan dalam dua keadaan, yaitu dengan keadaan tanpa penghalang dan berpenghalang serta membandingkan jarak responnya.

3. Tujuan dari pengujian ini yaitu untuk mengetahui sejauh mana sistem dapatmemenuhi kebutuhan user dan sejauh mana ketepatan jarak kontrol yang dapat dilakukan sistem.

\section{PEMBAHASAN}

\subsection{Hasil}

Hasil perancangan akan dibahas mengenai pengumpulan dan analisa data berdasarkan dari hasil pengujian terhadap alat yang telah dilakukan. Dari hasil pengujian yang telah didapatkan akan dibuat dalam sebuah tabel agar lebih mudah untuk dianalisasehingga dapat dijadikan sebagai acuan untuk menarik kesimpulan yang tepat.Sistem diuji untuk mengetahui kinerja dari jangkauan sistem bluetooth secara maksimal. Adapun hasil dari pengujian yang dilakukan sebagai berikut.Pengujian yang dilakukan adalah mengukur tegangan input dan output yang dikeluarkan setiap rangkaian. 
Tabel 4.1 Data Hasil Pengujian Tegangan Seluruh Rangkaian

\begin{tabular}{|l|l|l|l|l|}
\hline No & Bahan & $\begin{array}{l}\text { Tegangan } \\
\text { Input } \\
\text { (Accu) }\end{array}$ & $\begin{array}{l}\text { Teganga } \\
\mathrm{n} \\
\text { Catudaya }\end{array}$ & $\begin{array}{l}\text { Teganga } \\
\mathrm{n} \\
\text { Operasi }\end{array}$ \\
\hline 1 & Arduino & 13.08 VDC & $\begin{array}{l}8.98 \\
\text { VDC }\end{array}$ & $\begin{array}{l}7-12 \\
\text { VDC }\end{array}$ \\
\hline 2 & $\begin{array}{l}\text { Bluetoot } \\
\text { h }\end{array}$ & 13.08 VDC & $\begin{array}{l}8.98 \\
\text { VDC }\end{array}$ & $\begin{array}{l}3.3-6 \\
\text { VDC }\end{array}$ \\
\hline 3 & Catudaya & 13.08 VDC & $\begin{array}{l}8.98 \\
\text { VDC }\end{array}$ & 9 VDC \\
\hline 4 & Relay & 13.08 VDC & $\begin{array}{l}8.98 \\
\text { VDC }\end{array}$ & 5 VDC \\
\hline
\end{tabular}

Keterangan pada table 4.1 adalah hasil pengujian semua sumber tegangan aki motor 13.08 VDC yang kemudian diubah melalui rangkaian catudaya menjadi 8.92 VDC dan setelah itu tegangan akan melalui Arduino Uno, untuk tegangan VCC pada Arduino disambungkan sebagai sumber tegangan pada Relay dan tegangan 3.3 VDC untuk tegangan pada power Bluetooth HC-05.

\subsection{Pembahasan}

Pembahasan yang akan dilakukan pada perancangan ini adalah membahas dari setiappengujian dan langkah kerja seluruh rangkaian.

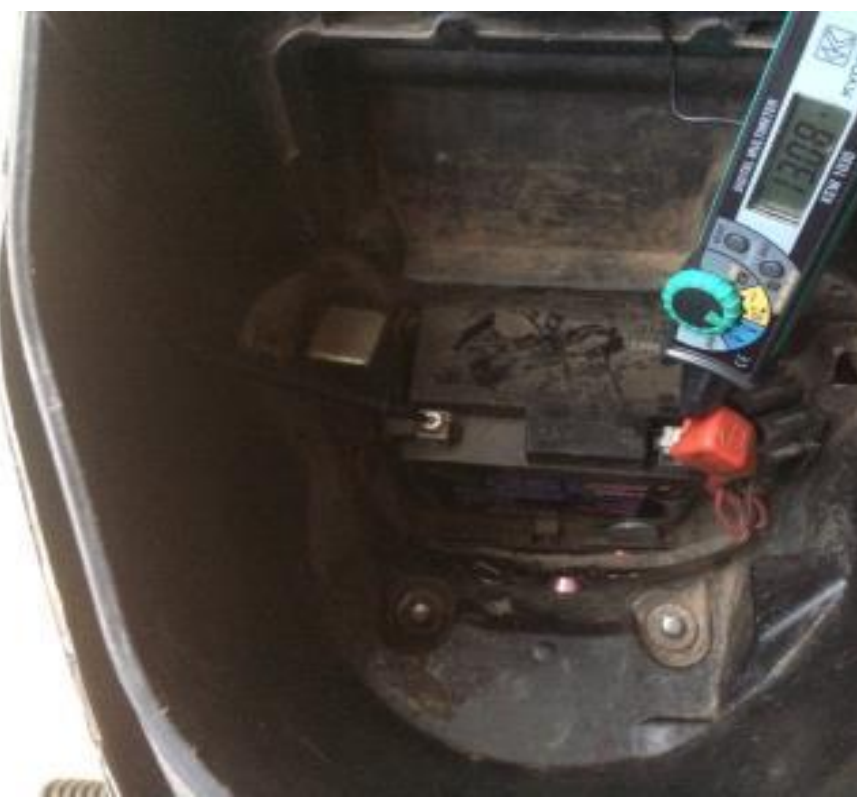

Gambar 4.1 Pengukuran

Tegangan Pada Aki

Pengukuran tegangan pada aki motor sebelum menghubungkan pada rangkaian catudaya.

\begin{tabular}{|l|l|l|}
\hline No & Jarak & Status \\
\hline 1 & 1 Meter & $\mathrm{R}$ \\
\hline 2 & 2 Meter & $\mathrm{R}$ \\
\hline 3 & 3 Meter & $\mathrm{R}$ \\
\hline 4 & 4 Meter & $\mathrm{R}$ \\
\hline 5 & 5 Meter & $\mathrm{R}$ \\
\hline 6 & 6 Meter & $\mathrm{R}$ \\
\hline 7 & 7 Meter & $\mathrm{R}$ \\
\hline 8 & 8 Meter & $\mathrm{R}$ \\
\hline 9 & 9 Meter & $\mathrm{R}$ \\
\hline 10 & 10 Meter & $\mathrm{R}$ \\
\hline 11 & 11 Meter & $\mathrm{R}$ \\
\hline 12 & 12 Meter & $\mathrm{R}$ \\
\hline 13 & 13 Meter & TR \\
\hline
\end{tabular}


Sigma Teknika, Vol.1, No.2 : 207-225

November 2018

E-ISSN 2599-0616

P ISSN 2614-5979

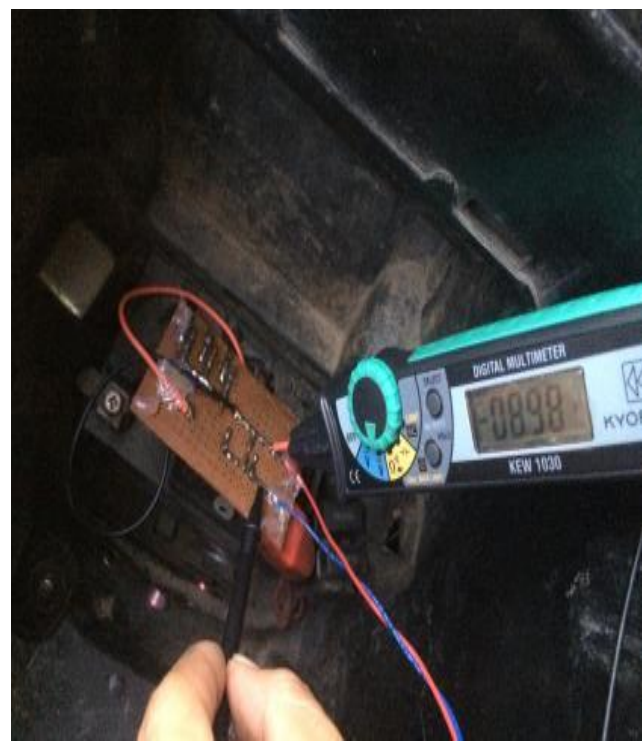

Gambar 4.2 Pengukuran setelah rangkaian catudaya

Pada Gambar 4.2 adalah pengukuran setelah tersambung dengan rangkaian catudaya untuk menurunkan tegangan pada Aki 12

\begin{tabular}{|l|l|l|}
\hline No & Jarak & Status \\
\hline 1 & 1 Meter & R \\
\hline 2 & 2 Meter & R \\
\hline 3 & 3 Meter & R \\
\hline 4 & 4 Meter & R \\
\hline 5 & 5 Meter & R \\
\hline 6 & 6 Meter & R \\
\hline 7 & 7 Meter & R \\
\hline 8 & 8 Meter & R \\
\hline 9 & 9 Meter & R \\
\hline 10 & 10 Meter & R \\
\hline 11 & 11 Meter & TR \\
\hline 12 & 12 Meter & TR \\
\hline 13 & 13 Meter & TR \\
\hline
\end{tabular}

VD

C

men

jadi

9

VD

C.

4.2 .

3

Pen

guji

an

Jara

$\mathrm{k}$
Respon

Pada pengujian ini bertujuan untuk mengukur seberapa jauh jarak respon maksimal pengontrolan oleh user pada kendaraan dengan kondisi tanpa penghalang dan berpenghalang yang dibuktikan pada tabel 4.2.

Tabel 4.2 Pengujian Sistem tanpa Penghalang

Tabel 4.3 Pengujian Sistem dengan Penghalang 
Sigma Teknika, Vol.1, No.2 : 207-225

November 2018

E-ISSN 2599-0616

P ISSN 2614-5979

menambahkan autentifikasi login untuk dapat mengakses fungsi remote. Selain itu juga diprogram sebuah aplikasi untuk ponsel android agar dapat mengirim password dan fungsi remote. Aplikasi pada android digunakan sebagaimedia antar muka antara user dengan perangkat control. Berikut adalah tampilan aplikasi yang dibuat.

4.2.1 Pengujian Koneksi Aplikasi

Pengujian ini dilakukan
untuk memastikan apakah dapat
terhubung dengan baik dan dapat
berjalan sesuai dengan perintah user.

- $\mathrm{R}=$ Respon

- $\quad \mathrm{TR}=$ Tidak Respon

\subsection{Pemrograman Perangkat}

\section{Lunak}

Pemrograman perangkat lunak dibagi menjadi dua, yaitu: pemrograman pada mikrokontroler dan pemrograman pada aplikasi android. Pemrograman pada mikrokontroler adalah untuk mengolah data yang diterima oleh mikrokontroler. Mikrokontroler diprogram agar dapat mengontrol secara penuh fungsi remote dan 
November 2018

E-ISSN 2599-0616

P ISSN 2614-5979

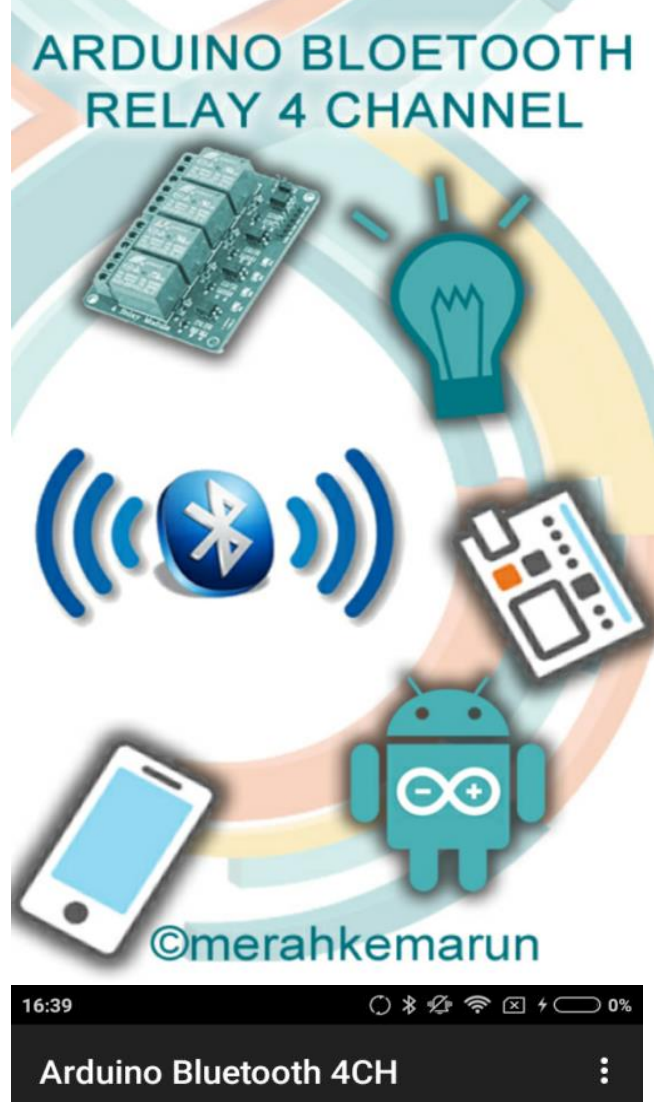

HC-05 98:D3:61:FD:37:B2
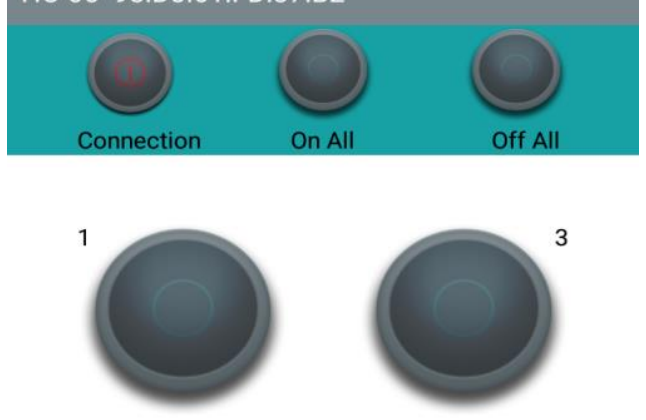

2

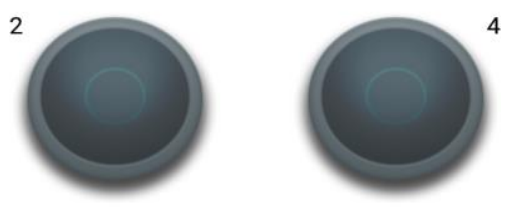

Gambar 4.1 Tampilan Login Aplikasi Gambar 4.1 Tampilan aplikasi android

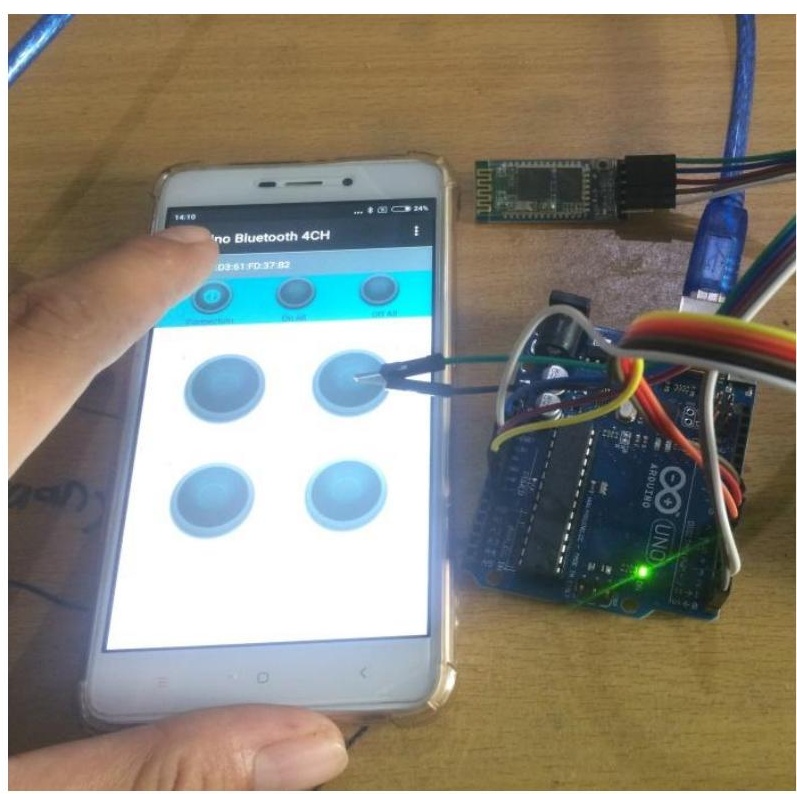

Gambar 4.3 Pairing dengan

perangkat Bluetooth

Ketika smartphone dapat menemukan perangkat Bluetooth HC05, maka dipastikan bahwa perangkat telah tersambung dan kemudian menekan tombol Connection untuk menghubungkan.

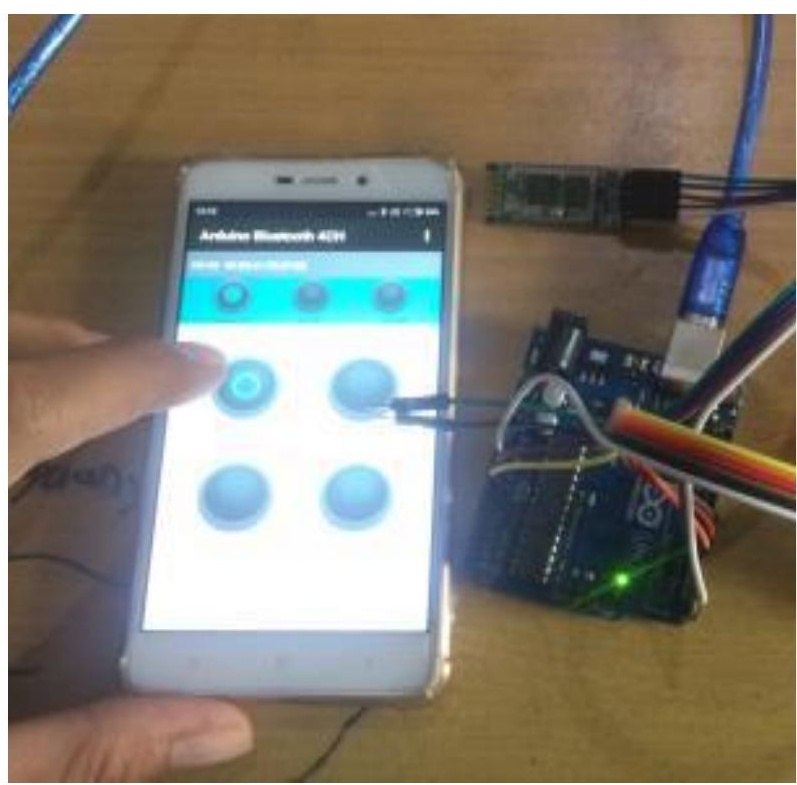


Gambar 4.3 Pengujian Relay 1

Pada gambar 4.3 adalah menunjukan bahwa relay 1 telah aktif yang ditandai dengan lampu indikator pada relay menyala dan difungsikan untuk menghidupkan sistem kelistrikan (Kontak) pada kendaraan.

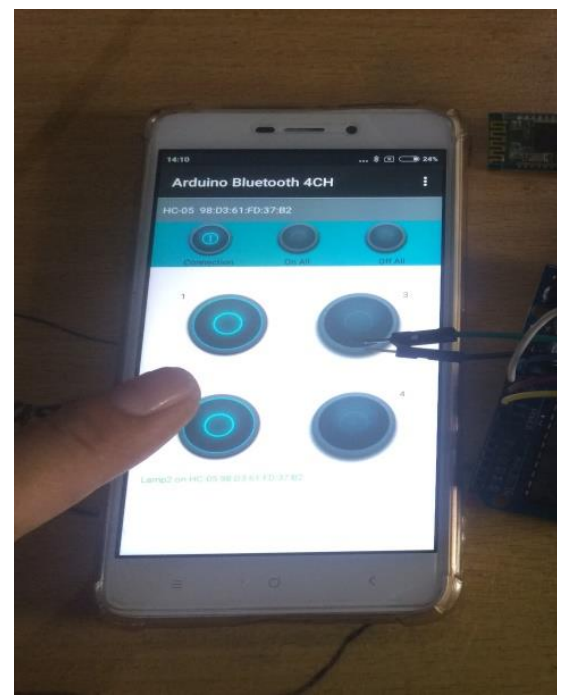

Gambar 4.4 Pengujian Relay 2

Pada Gambar 4.4 Menunjukkan bahwa relay 2 telah aktif dengan menekan tombol 2 yang ditandai dengan lampu indikator pada relay menyala dan difungsikan untuk menghidupkan kendaraan (Starter) dan ketika mesin hidup maka seterusnya untuk segera mamatikan relay 2 untuk memutus kembali aliran listrik yang terus-menerus untuk menghindari kerusakan pada starter motor.

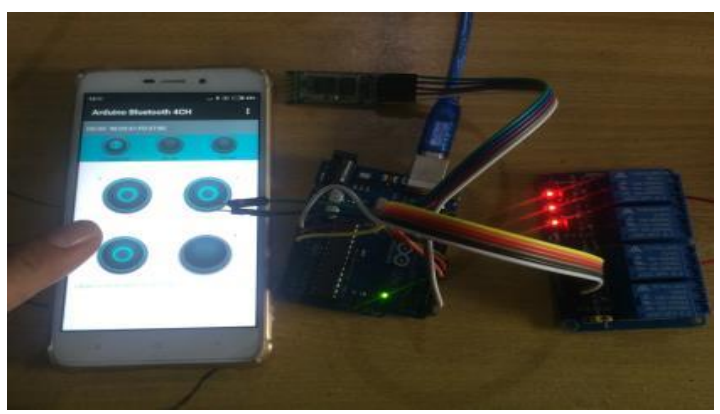

Gambar 4.5 Pengujian Relay 3

$$
\text { Pada Gambar }
$$

Menunjukkan bahwa relay 3 telah aktif dengan menekan tombol 3 yang ditandai dengan lampu indikator pada relay menyala dan difungsikan sebagai Klakson.

Semua tombol yang yang terdapat pada aplikasi tidak dapat difungsikan secara keseluruhan dan sistemnya dapat menekan dua kali untuk menghidupkan dan mematikan. Untuk memutuskan koneksi pada Bluetooth maka kembali menekan tombol Connection yang berarti smartphone tidak terhubung lagi dengan rangkaian.

\subsubsection{Pemograman pada Arduino} Uno

Berikut adalah kode program pada IDE Arduino yang digunakan dalam penelitian : 
int relay $6=1$;

int relay $7=2$;

int relay8 $=3$;

char kode;

void $\operatorname{setup}()\{$

pinMode (relay6, OUTPUT);

pinMode (relay7, OUTPUT);

pinMode (relay8, OUTPUT);

digitalWrite (relay6, HIGH);

digitalWrite (relay7, HIGH);

digitalWrite (relay8, HIGH);

Serial.begin(9600);

// put your setup code, to run once:
digitalWrite (relay7, HIGH);\}

else if $\left(\right.$ kode $\left.=={ }^{\prime} C^{\prime}\right)\{$

digitalWrite (relay8, HIGH);

\}

// put your setup code, to run repeatedly:

\section{DAFTAR PUSTAKA}

void $\operatorname{loop}()\{$

if (Serial.available ()$)\{$

kode $=$ Serial.read () ;

\}

if $\left(\right.$ kode $==$ ' $\left.1 '^{\prime}\right)\{$

digitalWrite (relay6, LOW);\}

else if $($ kode $==$ '2' $)\{$

digitalWrite (relay7, LOW);\}

else if $($ kode $==' 3 ')\{$

digitalWrite (relay8, LOW);

\}

else if $\left(\right.$ kode $\left.=={ }^{\prime} A^{\prime}\right)\{$

digitalWrite (relay6, HIGH);

[1]. Pratama, I Putu Agus Eka, 2014, Sistem informasi dan implementasinya, Informatika, Bandung.

[2]. Lusiana Citra Dewi, Wireless Technology Development: History, Now, And Then, 2011

[3]. BlueTooth Introduction; http://www.xilinx.com/esp/netw orks_telecom/blue tooth/tutorials.htm; tanggal access 6 April 2004.

else if $\left(\right.$ kode $\left.=={ }^{\prime} \mathbf{B}\right)\{$ 
[3] Riku Mettala; Bluetooth Protocol Stack; 1999

[4]. Taufik, Azzi, Mikrokontroler Arduino Uno, Online pada http://dialogsimponi.blogspot.c o.id/2014/11/normal-0-falsefalse-false-in-x-none-x.html, diakses pada tanggal 18 Februari 2016.

[5]. M.Tan, K.A. Masagca.,2011, "An Investigation of Bluetooth Security Threats", International Conference on Information Science and Applications, pp 17.

[6]. YuliaLeo \& Willyanto Santoso. Studi Dan Uji Coba Teknologi Bluetooth Sebagai Alternatif Komunikasi Data Nirkabel. Jurnal Informatika, 106 - 114. 2004

[7] Rusli, Ahmad "Implementasi Bluetooth HC-05 Untuk Mengurangi Tingkat Kecelakaan Pada Pengendara Sepeda Motor" skripsi, Fakultas Teknik Universitas Mercu Buana (2015)

[8] https://www.caratekno.com /2015/07/ pengertian arduino uno mikrokontroler.html
[9] Owen Bishop, 2004 , Dasardasar Elektronika, Erlangga, Jakarta

[10].

$$
\text { https://teknikelektronika.com/ }
$$
pengertian-power-supply-jeniscatu-daya

[11]. Mon, Y. (2015). The Bluetooth Based LED Control For Arduino Test Platform By Using Mobile APP. International Journal of Scientific \& Technology Research,4(6), 330-332. 